\title{
MECHANICAL TESTS OF FULL-SIZE FORT ST. VRAIN FUEL BLOCKS
}

\author{
by \\ H. R. W. COBB
}

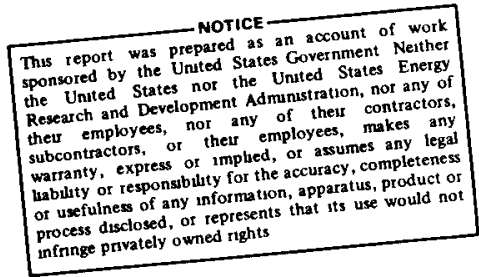

Prepared under

Contract E(04-3)-633

for the San Francisco Operations Office

U.S. Energy Research and Development Administration 


\section{DISCLAIMER}

This report was prepared as an account of work sponsored by an agency of the United States Government. Neither the United States Government nor any agency Thereof, nor any of their employees, makes any warranty, express or implied, or assumes any legal liability or responsibility for the accuracy, completeness, or usefulness of any information, apparatus, product, or process disclosed, or represents that its use would not infringe privately owned rights. Reference herein to any specific commercial product, process, or service by trade name, trademark, manufacturer, or otherwise does not necessarily constitute or imply its endorsement, recommendation, or favoring by the United States Government or any agency thereof. The views and opinions of authors expressed herein do not necessarily state or reflect those of the United States Government or any agency thereof. 


\section{DISCLAIMER}

Portions of this document may be illegible in electronic image products. Images are produced from the best available original document. 


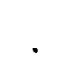




\begin{abstract}
A simple hydraulic pressure test of the webs in a Fort St. Vrain (FSV) fuel block shows that no catastropic fracture occurs when the fuel holes are pressurized either individually or as a contiguous six-hole array. There is a small volume increase in the coolant hole common to the fuel holes being tested. Failure, as defined by a decrease in structural resistance to further hydraulic pressure, occurs at some pressure between 500 and 1320 psi in individually tested fuel holes, depending upon the condition of adjacent holes.

When a FSV fuel block configuration consisting of a central fuel hole with six surrounding fuel and coolant holes is subjected to a uniaxial tensile or compressive load, internal hoop pressures up to the bursting strength of the material reduce the axial strength of the configuration by less than $13 \%$.
\end{abstract}


INTRODUCTION

The graphite moderator blocks of the Fort St. Vrain High-Temperature Gas-Cooled Reactor were machined from extruded logs of Great Lakes Carbon Company H-327 graphite. Grade H-327 was manufactured with calcined needle coke and bonded and impregnated with coal-tar pitch. Arrays of 0.5-in.diameter fuel holes and 0.625-in.-diameter coolant holes are aligned axially through the hexagonal cross section of the block (Fig. 1). The basic array is a central fuel hole with six alternate fuel and coolant holes equi-pitched on a 1.48-in. Bolt Circle Diameter (BCD). This configuration produces a minimum web thickness between adjacent fuel and coolant holes of 0.1775 in.

\section{EXPERIMENTAL}

\section{Mechanical Testing}

Tests have been performed to assess the effect of cracked webs on the structural integrity of an unirradiated block. A simple approach is hydraulic burst testing of a block using a pressurizing sleeve in the fuel hole positions. The effect of variation in the web thickness and geometry may be estimated in this manner.

Hydraulic pressures for producing a hoop-stress-only condition in the walls of the fuel holes were achieved by internally pressurizing rubber sleeves fitted to the full length of the fuel hole but free to expand along the axial direction. Each pressure sleeve was centered about a mandrel and sealed at the end by o-ring fittings. The fuel holes were pressure tested individually or in clusters of six surrounding a central coolant hole. An 


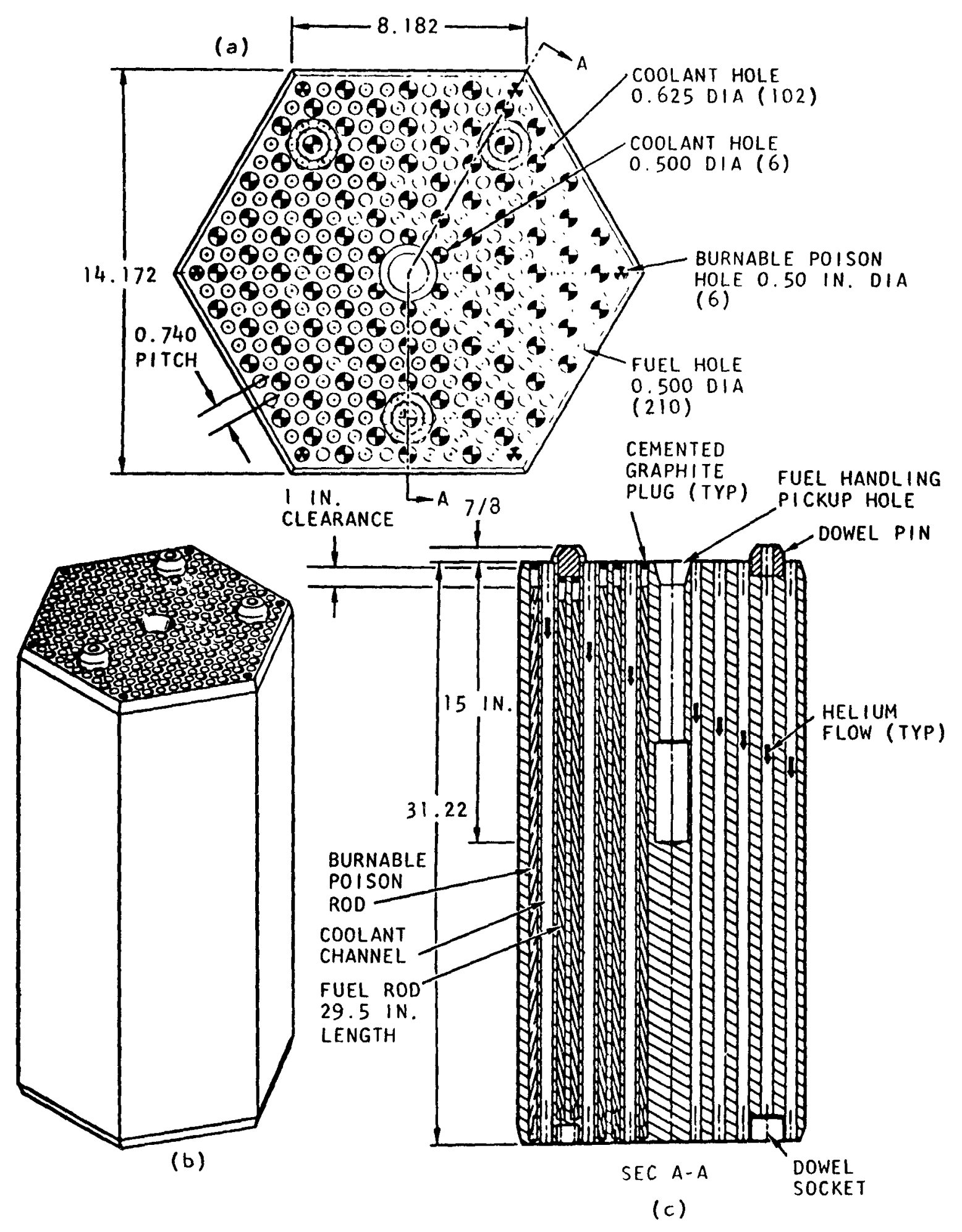

Fig. 1. FSV fuel block 
acoustic sensing crystal was attached to the block, and amplified signals indicated the onset of fracture in the webs. The pressures required to produce various degrees of cracking intensity as indicated electronically were also recorded.

\section{Pressure Test Results}

The burst pressure of the graphite web under a hydraulically applied load was considered to be that pressure at which there was no further resistance to expansion of the internal pressure sleeve. Burst pressures ranged between 500 and 1320 psi for individually tested holes and 680 and 865 psi for the six-hole clusters (Fig. 2). Around the periphery of the block the burst pressures were below the average values, even though the measured tensile strength of the graphite at this position is maximum (Ref. 1). When six holes common to a central coolant hole were pressurized from a single manifold, the burst pressures were lower than most of the single-hole burst pressures. However, when repressurized individually, the unfailed holes in the previously tested clusters failed at approximately the average burst pressures for individually tested holes.

The first acoustic evidence that cracking was taking place within the webs of the fuel block occurred at hydraulic pressures between 200 and 400 psi.

\section{Damage Effects}

After $83 \%$ of all the fuel holes in FSV fuel block No. 1-0072 (see Fig. 2) had been pressurized to produce fracture by hoop stress, the block could still be handled in the standard manner by lifting through the central lifting hole. When the fuel holes of this block were loaded with simulated FSV fuel particles and an additional weight of lead (Fig. 3) equivalent to the weight of fuel in a block, no handling problems or spillage of FSV fuel-particlesized powders was observed. 


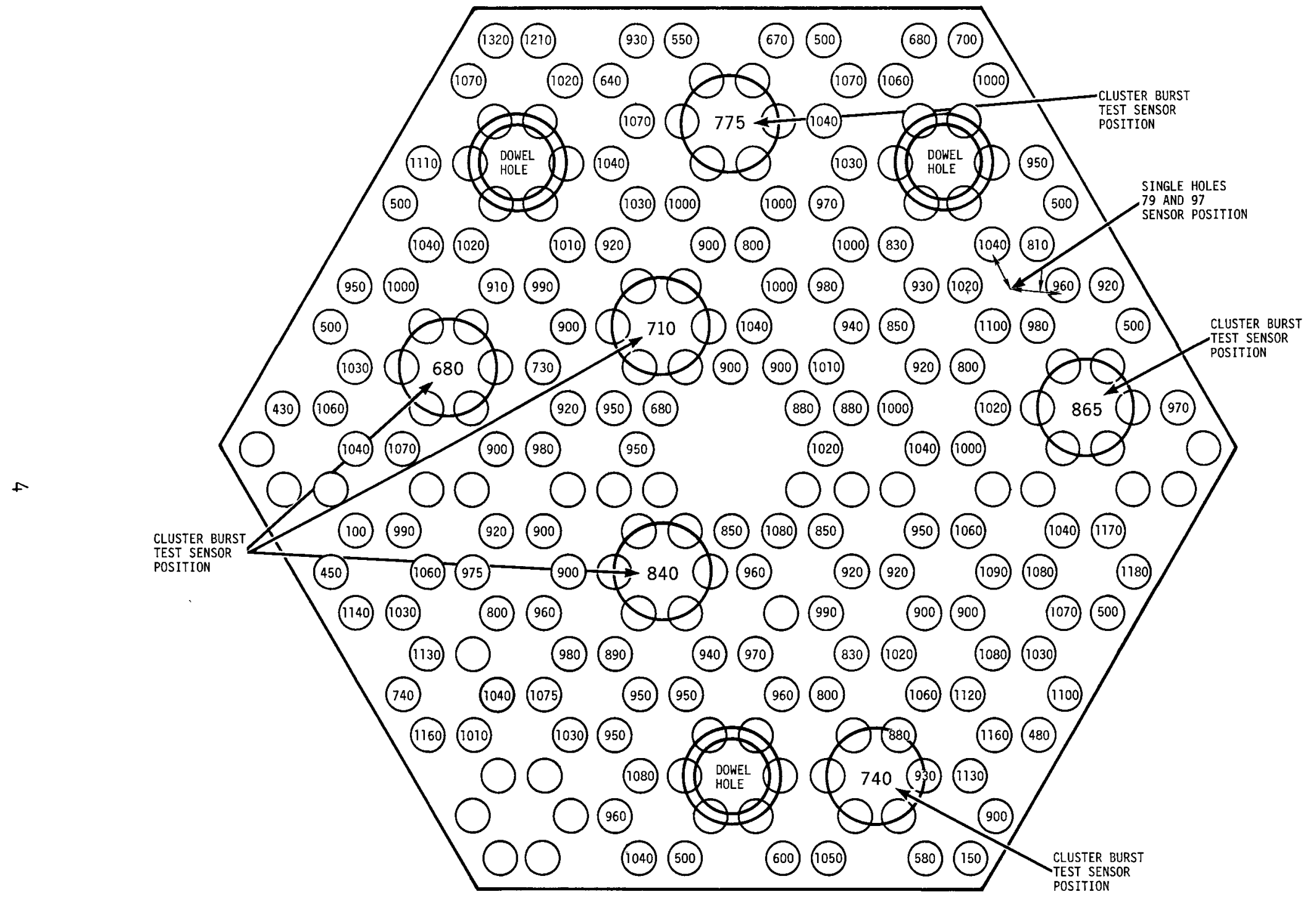

Fig. 2. Burst pressures of fuel holes in FSV fuel block subjected to hydraulic pressure tests either individually or in clusters of six adjacent holes around a central coolant hole 


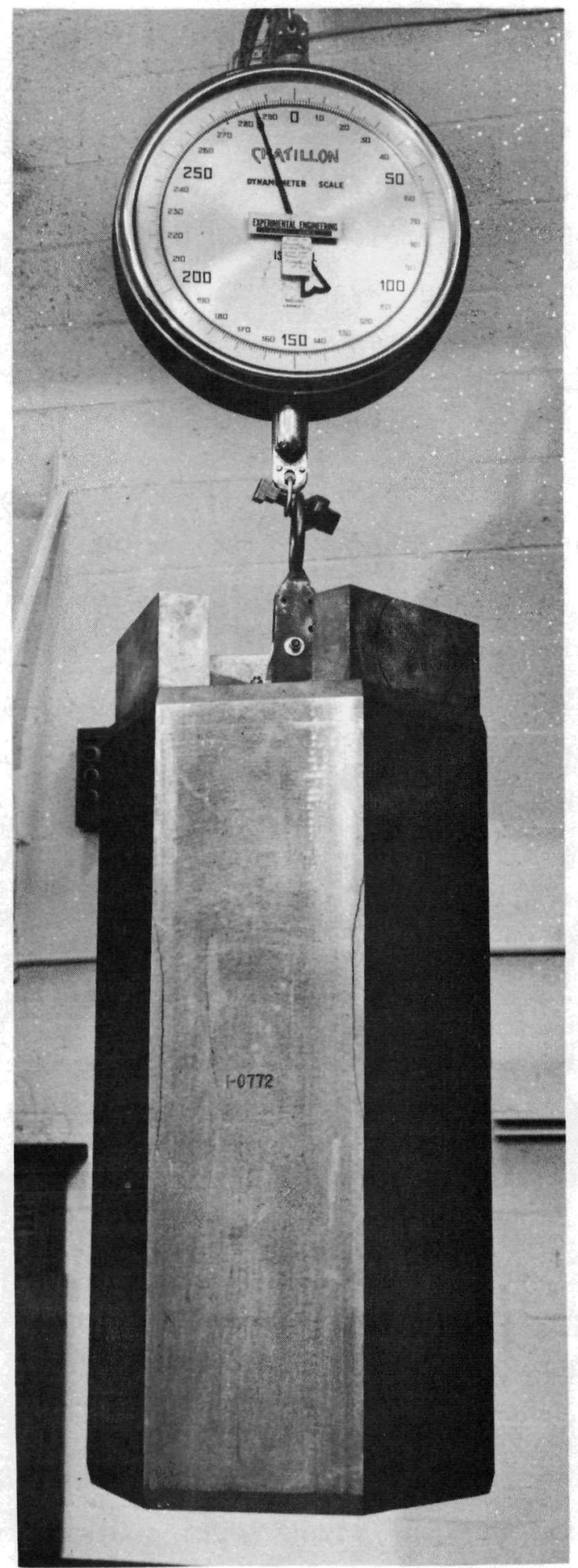

HT92432

Fig. 3. Weighted FSV fuel block containing $83 \%$ fractured fuel holes suspended by standard lifting tool 
The appearance of a fractured graphite web, as shown in Fig. 4, and the handling experiment indicate that a small crack in a web does not necessarily allow the passage of fuel particles into the coolant hole. The example shown in Fig. 4 is typical of the largest crack observed in the fuel block test, where burst loads had just exceeded the fracture stress of the graphite. No attempt was made to promote catastrophic fracture by the use of higher loading rates.

\section{Biaxial Loading}

The effects of independently acting biaxial loads were studied on sections of graphite machined from a FSV fuel block. The test samples (Fig. 5) were manufactured to permit tensile or compressive loads to be applied with an Instron test machine in the longitudinal direction with an independently acting hydraulic pressure applied in the central fuel hole. The results show that longitudinal compressive or tensile stress has no significant effect on the hoop pressure at web fracture of the assembly (Fig. 6). In hoop burst tests taken to fracture, visible cracks normal to the principal stress were observed to separate (Fig. 7). The most detrimental type of failure observed was intrusion of a segment of a graphite web into an adjacent coolant hole (Fig. 8). However, no further deformation took place in the region, shown in Fig. 7, before cracking occurred at other regions on the perimeter of the hole.

\section{DISCUSSION}

The wall thickness of the FSV coolant and fuel hole test array ranges from $0.17 \mathrm{in.} \mathrm{to} \mathrm{the} \mathrm{maximum} \mathrm{thickness} \mathrm{for} \mathrm{the} \mathrm{configuration} \mathrm{of} \mathrm{six} \mathrm{locations}$ around the fuel hole. An equivalent thick-shell cylindrical wall thickness can be derived empirically by burst-testing a series of cylinders with various wall thicknesses. The wall thickness at which the burst pressure equals that in the hole-array samples is the equivalent wall thickness for the hole array. The results of a series of such tests are shown in Fig. 9. The equivalent wall thickness for the hole array was found to be between 0.20 and $0.25 \mathrm{in}$. This determination permits an estimate of the hoop and 


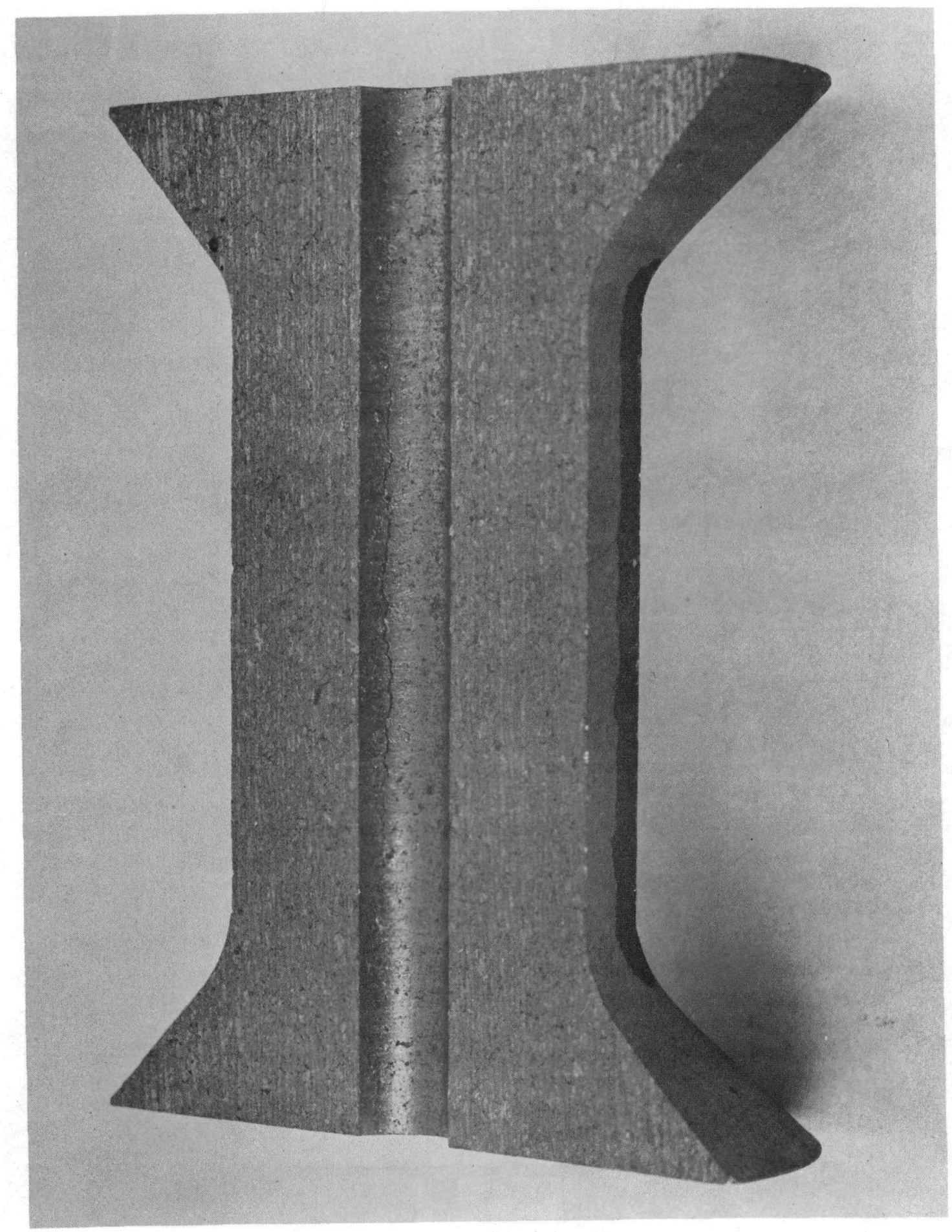

HT92430

Fig. 4. Typical fracture in FSV fuel block graphite web at a maximum hoop stress of 2000 psi 


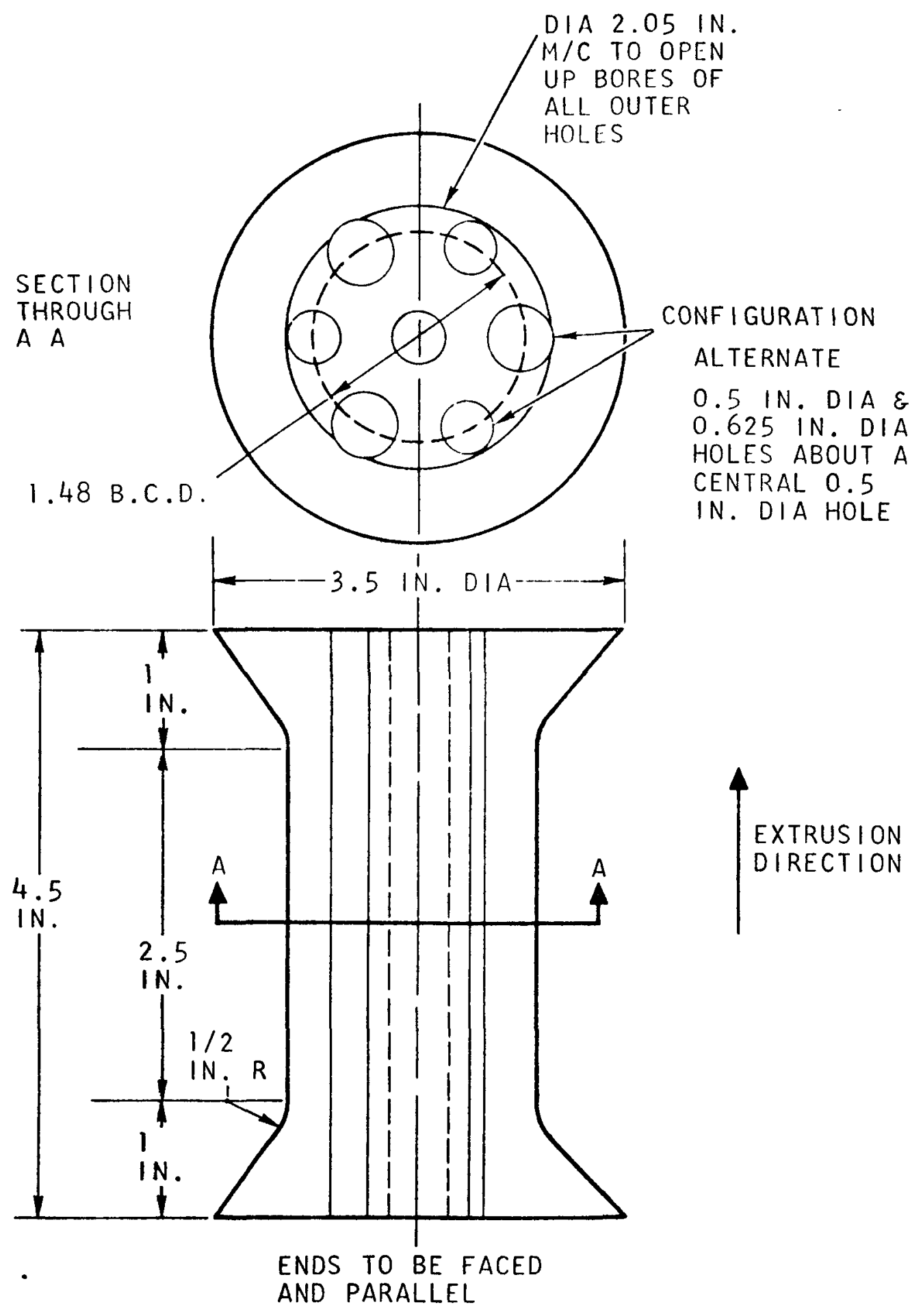

Fig. 5. Test section of H-327 graphite from FSV fuel block showing basic array of coolant and fuel holes. Scale $=1 / 1$. 


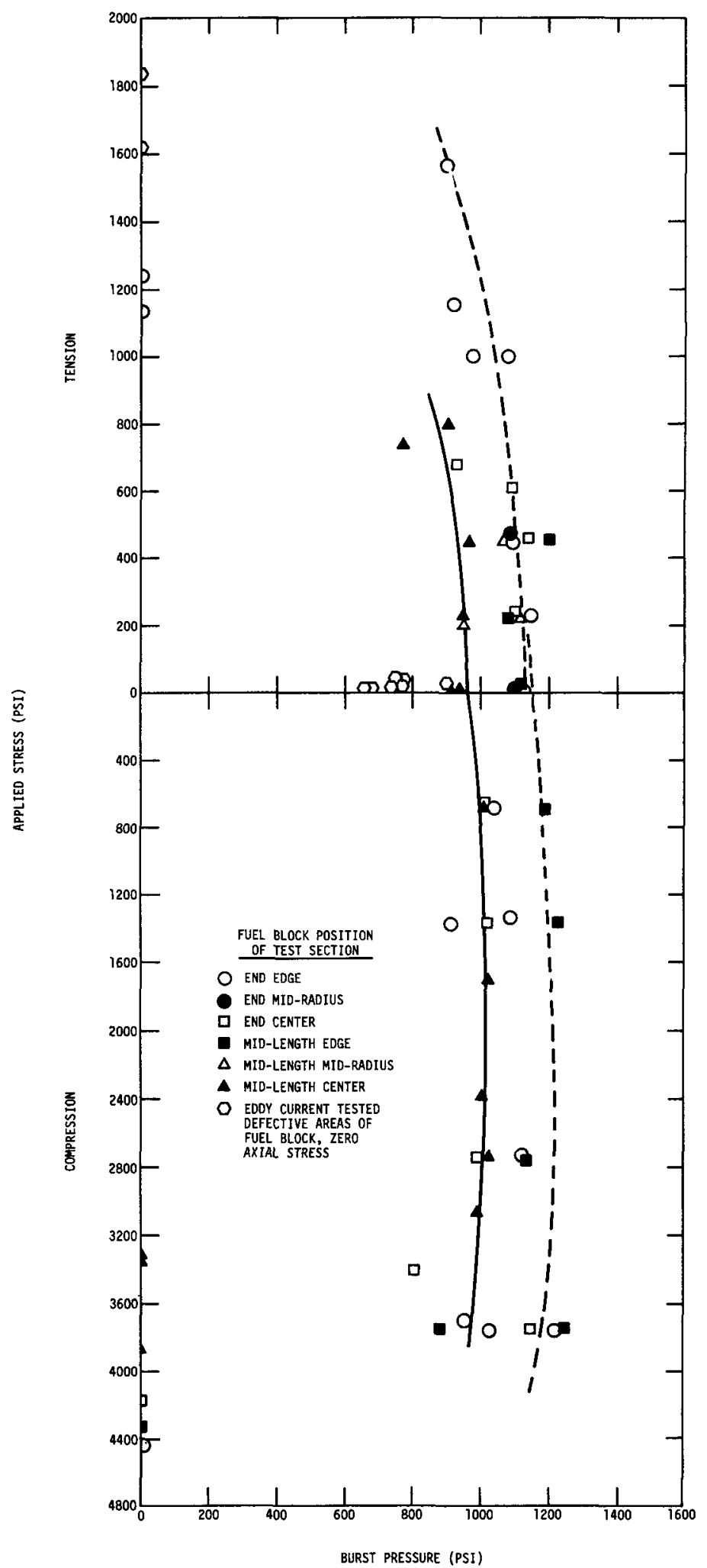

Fig. 6. Uniaxial tension or compression versus fracture pressure for fuel block (single array of holes) 


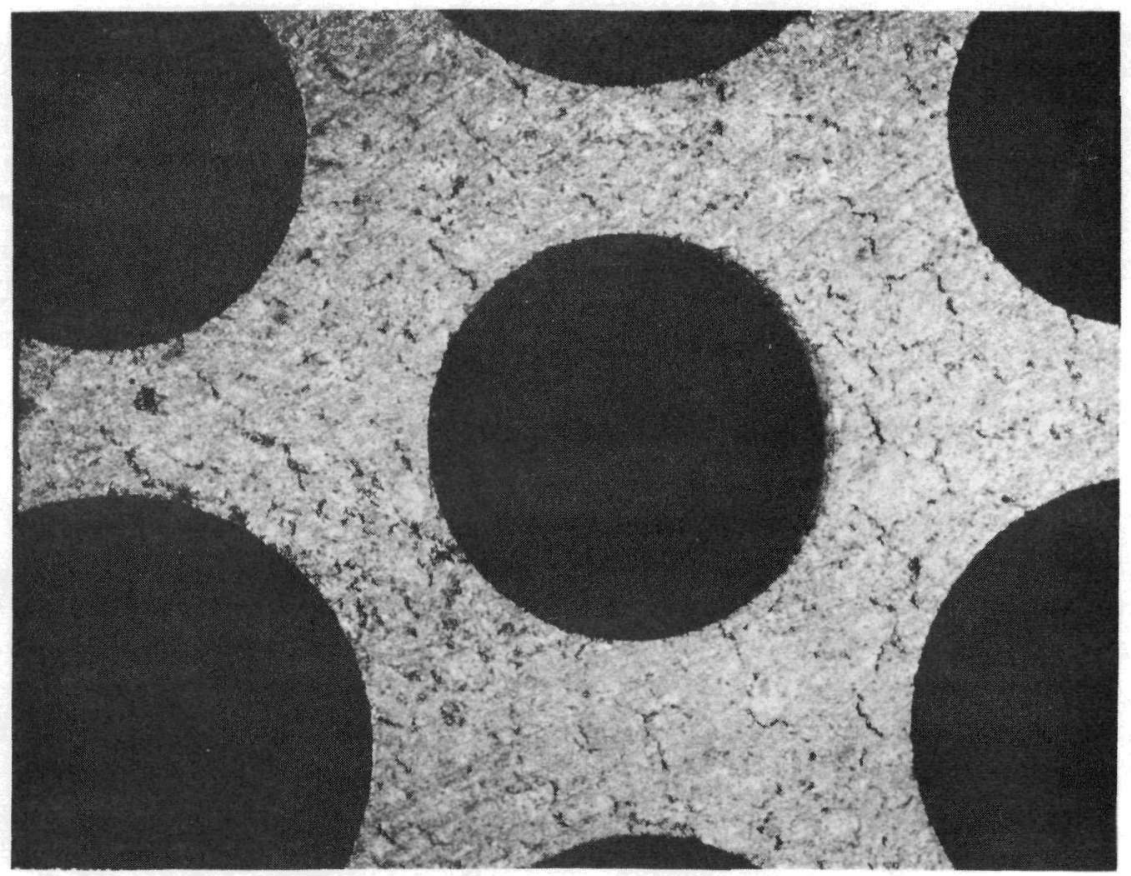

M32817-3

(a)

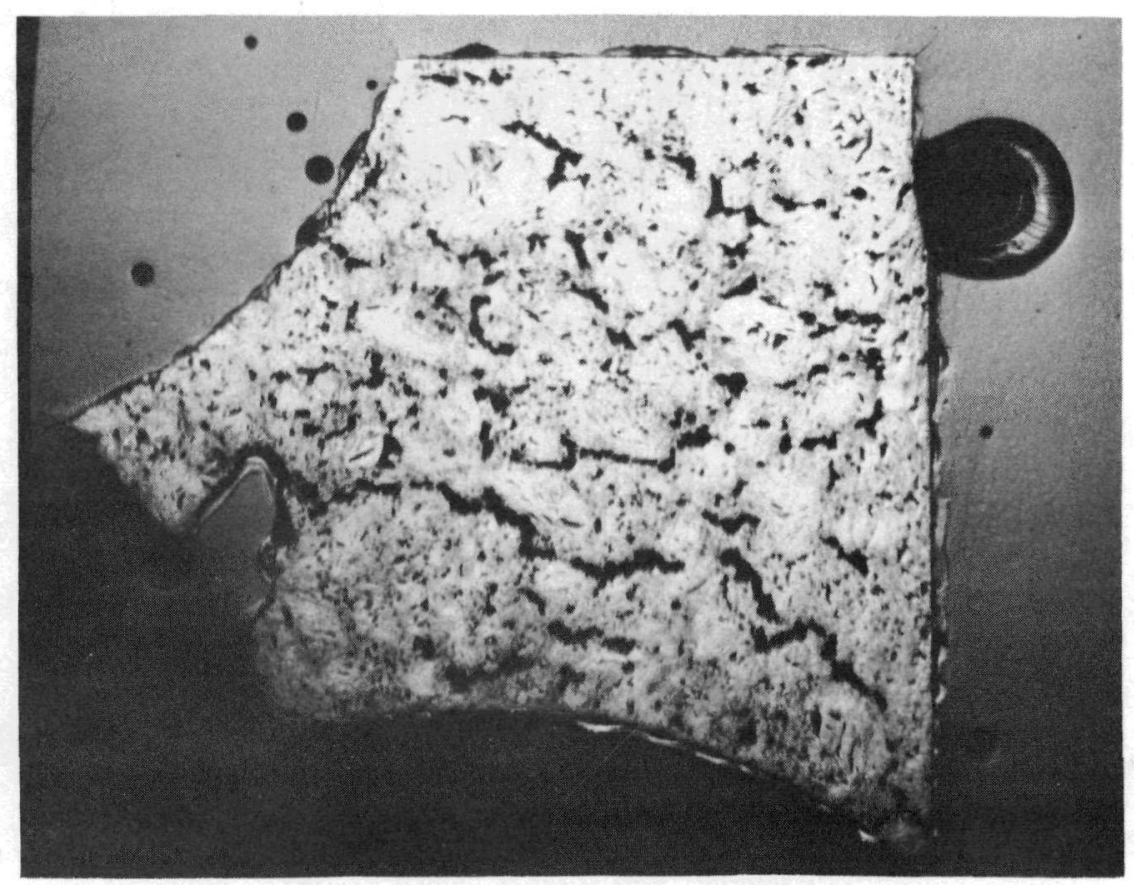

M33697-3

(b)

Fig. 7. Cracks observed in FSV fuel block web subjected to hoop stress: (a) prior to stress; (b) stressed to failure 


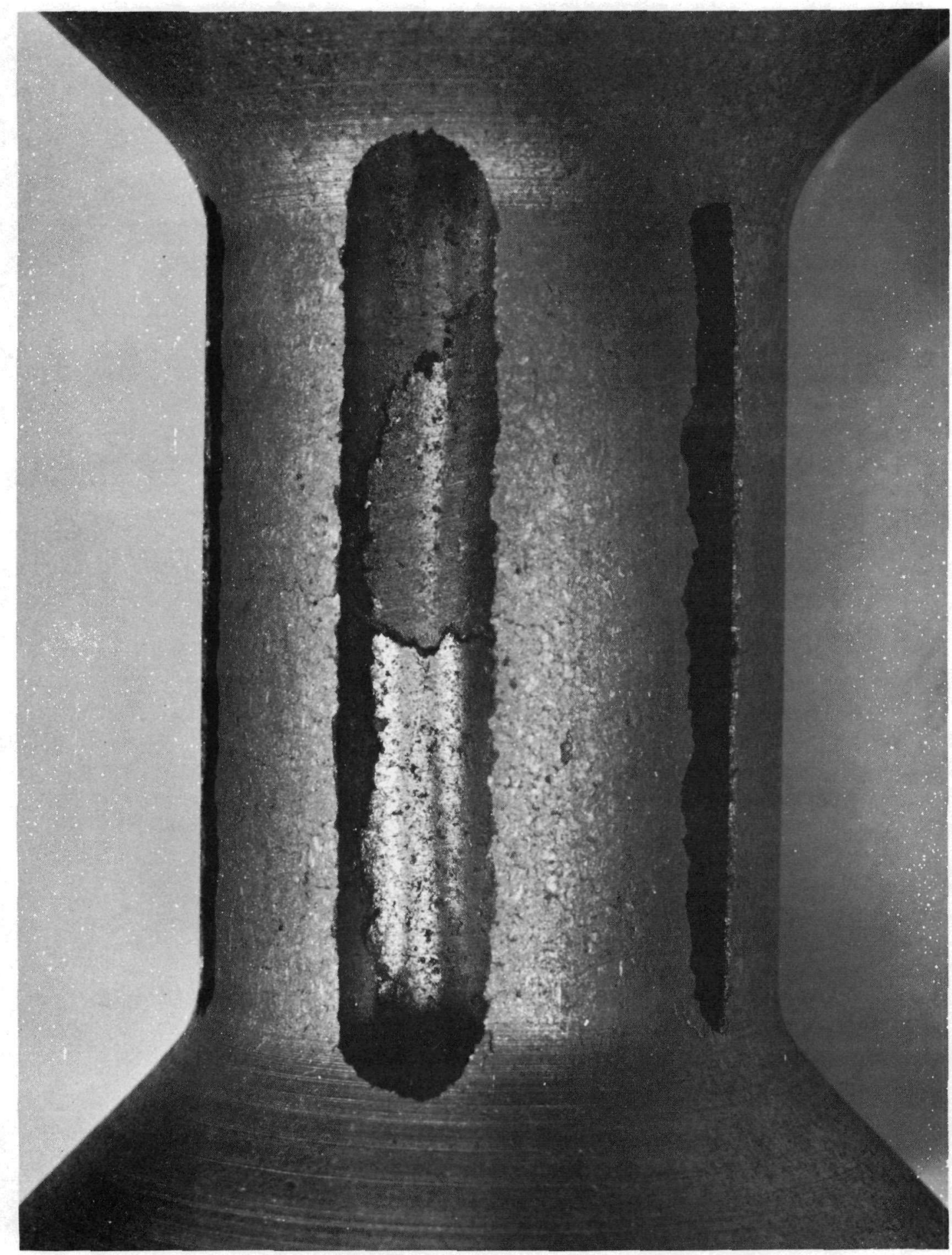

HT92317

Fig. 8. Damage from failure of fuel hole, showing intrusion of graphite into coolant hole 


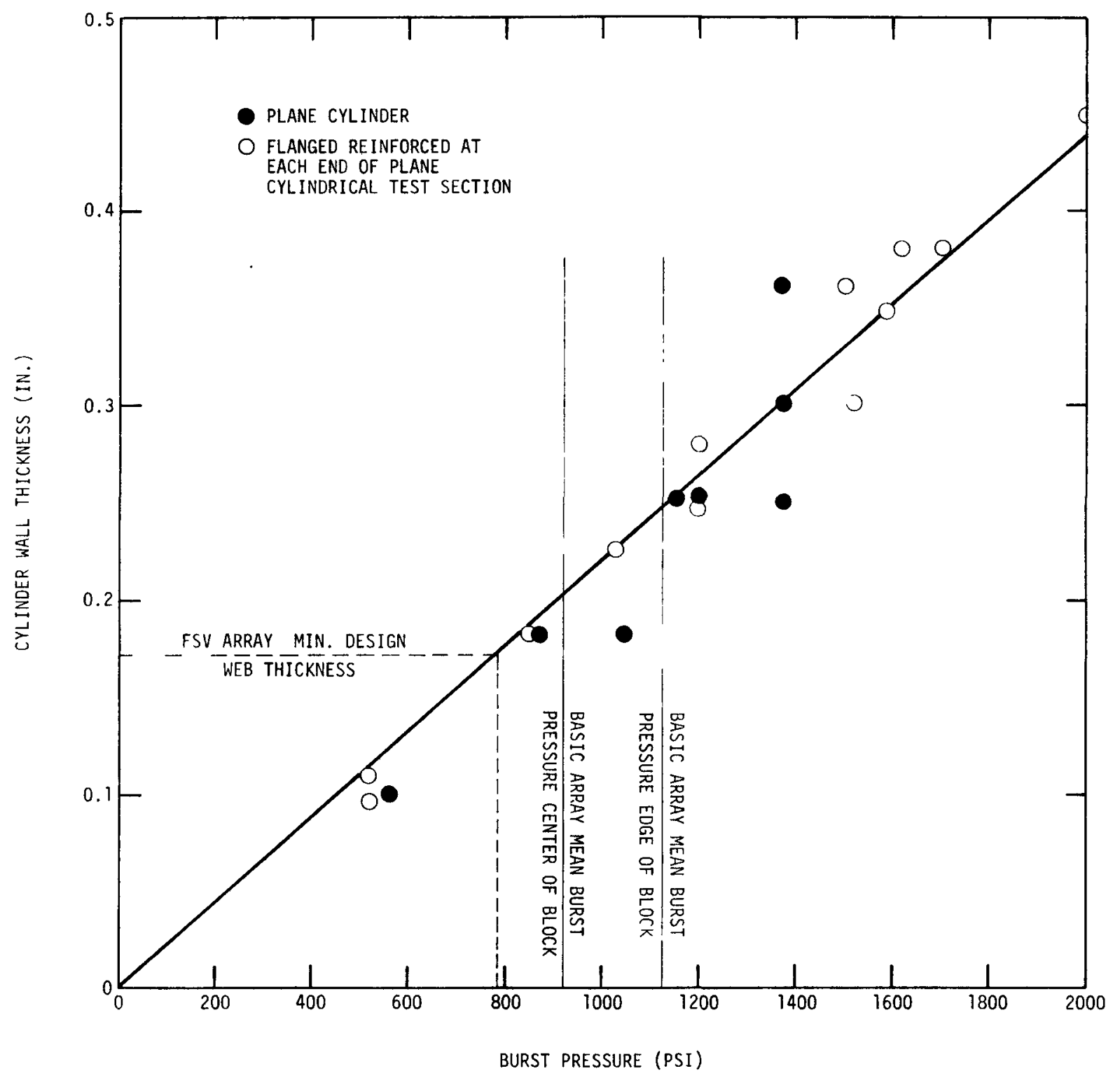

Fig. 9. Hoop-stress-induced burst pressures in H-327 graphite thick-shell cylinders 
radial stresses developed in the graphite. These stresses are at a maximum at the inside diameter of the fuel hole. (These tests also demonstrated that the reinforced ends of the test specimens had no effect on the ultimate breaking strength of the graphite within the test section.)

From thick-shell theories, the radial stress in the web at position $r$ is

$$
\frac{\mathrm{pr}_{1}^{2}}{\mathrm{r}_{2}^{2}-\mathrm{r}_{1}^{2}}\left(1-\frac{\mathrm{r}_{2}^{2}}{\mathrm{r}^{2}}\right)
$$

and the maximum hoop stress is

$$
p \frac{\left(r_{1}^{2}+r_{2}^{2}\right)}{\left(r_{2}^{2}-r_{1}^{2}\right)}
$$

where $p$ is the hydraulic pressure and $r_{1}$ and $r_{2}$ are the inner and outer radii of the equivalent cylinder.

The maximum web hoop stress in the basic array burst test specimens, based on the empirically derived thickness of 0.2 to $0.25 \mathrm{in}$., is 1.8 times the burst pressure. The maximum radial stress is compressive and equal to 1.0 times the burst pressure. Estimates of the ultimate hoop stress in the webs of a fuel block range from 1200 to $2376 \mathrm{psi}$ and are consistently higher than the standard uniaxial test results.

\section{CONCLUSIONS}

The fracture stress in the webs of an unirradiated FSV fuel block have been induced by introducing hoop loads in the fuel holes. When $83 \%$ of the webs were fractured at some position along the length of a block, the block remained handleable and suffered no loss of simulated fuel from the block or transfer of particles from the fuel holes to the coolant channels through the fractured web. 
For a hoop-stress-only condition of stress in a fuel block, the burst pressures at web fracture were as high near the center of the block as at the edges, where there is less reinforcement of material around the holes. The measured hoop stress at fracture is higher than that indicated by uniaxial tensile tests.

The graphite surrounding a central fuel hole within the perimeter of six alternate fuel and coolant holes in a FSV fuel block has been demonstrated to have an effective thickness equivalent to 0.2 to $0.25 \mathrm{in}$. cylindrical form.

When a portion of a FSV fue1 block configuration, consisting of a central fuel hole with six surrounding fuel and coolant holes was subjected to a uniaxial tensile or compressive load, internal hoop pressures up to the fracture strength of the webs were reduced by less than $13 \%$ from the fracture strength without axial loading. 
REFERENCES

1. Cobb, H. R. W., G. B. Engle, and S. J. S. Parry, "Characterization of Production-Grade H-327 Graphite for HTGR Design," Proceedings of The Conference on Continuum Aspects of Graphite Design, Gatlinburg, Tennessee, November 9-12, 1970 (CONF 701105). 